\title{
Evapotranspiração e coeficiente de cultura do feijão-caupi sob sistema de cultivo convencional e plantio direto
}

\author{
Aderson Soares de Andrade Junior ${ }^{1(*)}$, Edson Alves Bastos ${ }^{1}$, Marinete Martins de Sousa Monteiro ${ }^{2}$ e \\ Josimar Soares da Silva Junior ${ }^{2}$ \\ ${ }^{1}$ Embrapa Meio-Norte, Avenida Duque de Caxias, 5.650, Bairro Buenos Aires, Caixa Postal 001, CEP 64008-780 Teresina, PI. \\ E-mails: aderson.andrade@embrapa.br e edson.bastos@embrapa.br \\ ${ }^{2}$ UFPI-Programa de Pós-graduação em Agricultura Tropical, Campus Universitário Ministro Petrônio Portela, Bairro Ininga, CEP 64049-550 Teresina, PI. \\ E-mails: marinettmartins@hotmail.com e josimarssjunior@gmail.com \\ ${ }^{(*)}$ Autor para correspondência.
}

\section{INFORMAÇÕES}

\section{História do artigo:}

Recebido em 23 de junho de 2018

Aceito em 2 de dezembro de 2018

\section{Termos para indexação:}

balanço hídrico

risco climático

$\mathrm{Kc}$

demanda hídrica

\section{RESUMO}

O objetivo deste estudo foi quantificar e comparar a evapotranspiração (ETc) e os coeficientes de cultura (Kc), bem como avaliar a economia de água proporcionada pela adoção do sistema de cultivo plantio direto em relação ao cultivo convencional na cultura do feijão-caupi em Teresina, PI. O estudo foi conduzido no Campo Experimental da Embrapa Meio-Norte, em Teresina, Piauí, Brasil $\left(5^{\circ} 05\right.$ 'S, 42²9'W e 74,40 m de altitude), de junho a agosto de 2016, em um Argissolo Amarelo-Vermelho eutrófico, textura arenosa. A ETc diária foi medida por meio da diferença diária do armazenamento de água no solo, em camadas de 0,1 m, até a profundidade de 0,6 m. A ETc do feijão-caupi sob plantio direto é 14,9\% inferior ao cultivado sob preparo convencional. Houve redução média de 16,9\% no Kc do feijão-caupi cultivado sob plantio direto em relação ao sistema de preparo convencional.

(C) 2018 SBAgro. Todos os direitos reservados.

\section{Introdução}

O feijão-caupi [Vigna unguiculata (L.) Walp] é uma cultura de importância socioeconômica para as regiões Nordeste e Norte do Brasil, devido ao seu baixo custo de produção e por ser importante fonte de proteína para as populações de baixa renda dessas regiões (Freire Filho, 2011).

Um dos grandes problemas encontrados nas regiões de cultivo do feijão-caupi, principalmente no Nordeste e Norte brasileiros, é a irregularidade do período chuvoso associada a outros fatores como solos arenosos, tempera- turas elevadas e manejo inadequado, os quais contribuem para o baixo rendimento de grãos da cultura (Cardoso et al., 2017).

O sistema de plantio direto pode ser considerado vantajoso em relação ao plantio convencional para a cultura do feijão-caupi, por utilizar resíduos de cultura para cobertura do solo com a finalidade de manter a umidade, diminuindo o risco da cultura ao déficit hídrico, como também maximizando a eficiência do uso da água. Outra vantagem do plantio direto em palhada é a redução da temperatura do solo, diminuindo o efeito drástico das condições climá- 
ticas desfavoráveis ao desenvolvimento da cultura (Simidu et al., 2010).

A presença de palhada na superfície do solo, em quantidade adequada, é também de grande importância na agricultura irrigada. Ela altera a relação solo-água, reduzindo a taxa de evapotranspiração das culturas, principalmente nos estádios em que seu dossel não cobre totalmente o solo, o que resulta em redução na frequência de irrigação e em economia nos custos de operação do sistema de irrigação (Stone et al., 2006).

Estudos foram executados visando avaliar os efeitos da adoção do plantio direto sobre a eficiência do uso, economia de água e manejo de irrigação em feijão-comum ( $P h a-$ seolus vulgaris L.) em comparação a outros sistemas de cultivo (Barros e Hanks, 1993; Stone e Moreira, 2000; Andrade et al., 2002, Bizari et al., 2009). Esses autores concluíram ocorrer economia de água de $14 \%$ a $30 \%$, dependendo do porte da planta, bem como observaram redução no número de irrigações e aumento do turno de irrigação, a partir de $50 \%$ de cobertura da superfície do solo pela palhada. Porém, a literatura evidencia que há carência de estudos nessa linha com o feijão-caupi.

O objetivo deste estudo foi quantificar e comparar a evapotranspiração e os coeficientes de cultura, bem como avaliar a economia de água proporcionada pela adoção do sistema de cultivo plantio direto em relação ao cultivo convencional na cultura do feijão-caupi em Teresina, PI.

\section{Material e Métodos}

O estudo foi conduzido no Campo Experimental da Embrapa Meio-Norte, em Teresina, Piauí, Brasil (505 'S, $42^{\circ} 29^{\prime} \mathrm{W}$ e 74,40 $\mathrm{m}$ de altitude), de junho a agosto de 2016 , utilizando sistemas convencional e plantio direto do feijão-caupi. o clima da região, segundo a classificação climática de Thornthwaite e Mather, é C1sA'a. Considerando os registros históricos de 1980 a 2014, apresenta temperatura média anual de $28,1^{\circ} \mathrm{C}$ e precipitação média anual de 1.342,4 mm (Bastos e Andrade Júnior, 2016).

O solo da área experimental é um Argissolo Amarelo-Vermelho eutrófico, com relevo suave de 3\% de declive (Melo et al., 2014). As análise granulométrica e química do solo são apresentadas nas Tabelas 1 e 2, respectivamente. Dois experimentos foram conduzidos sob sistemas convencional e de plantio direto. Cada sistema de cultivo ocupou uma área de 0,4 ha. Utilizou-se a cultivar BRS
Tabela 1. Características granulométricas do solo da área experimental.

\begin{tabular}{|ccccc|}
\hline \multirow{2}{*}{ Prof. $(\mathbf{m})$} & \multicolumn{4}{c}{ Granulometria $\left(\mathbf{g ~ k g}^{-1}\right)$} \\
& Areia Grossa & Areia Fina & Silte & Argila \\
\hline $0,0-0,2$ & 451,8 & 190,4 & 164,5 & 193,3 \\
\hline $0,2-0,4$ & 471,3 & 180,2 & 168,0 & 178,7 \\
\hline
\end{tabular}

Itaim, cuja semeadura ocorreu em 24/06/2016, em um espaçamento de $0,5 \mathrm{~m}$ entre fileiras, com densidade de 20 plantas $\mathrm{m}^{-2}$ (200.000 plantas ha-1).

o preparo do solo no sistema convencional de cultivo consistiu em aração e gradagem. Na área sob sistema de plantio direto foram utilizadas palhada de sorgo e braquiária no solo. A adubação de fundação foi realizada com 50 $\mathrm{kg} \mathrm{ha}^{-1}$ de $\mathrm{P}_{2} \mathrm{O}_{5}$ e $40 \mathrm{~kg} \mathrm{ha}^{-1}$ de $\mathrm{K}_{2} \mathrm{O}$ (Melo e Cardoso, 2017).

As irrigações foram realizadas por um sistema de aspersão convencional fixo, com aspersores de impacto, bocais de 4,4 mm x 3,2 mm e vazão de 1,59 $\mathrm{m}^{-3} \mathrm{~h}^{-1}$, a uma pressão de $3,0 \times 10^{5} \mathrm{~Pa}$, espaçados $12 \mathrm{~m} \times 12 \mathrm{~m}$. A evapotranspiração de referência (ETo) foi estimada com base nos dados climáticos médios diários de temperatura do ar, umidade relativa do ar, radiação solar global e velocidade do vento obtidos de uma estação meteorológica automática instalada próximo ao experimento. A irrigação foi aplicada repondo-se a evapotranspiração da cultura (ETc) determinada com base na ETo estimada pelo método de Penman-Monteith (Allen et al., 1998) e nos coeficientes de cultura de feijão-caupi recomendado pela FAO (Allen et al., 1998). As irrigações foram efetuadas as segundas, quartas e sextas-feiras, repondo-se a ETc do período anterior a última irrigação. No período compreendido entre a semeadura até 11 dias após a semeadura (DAS) do feijão-caupi, fez-se irrigações diárias. Para quantificação da lâmina e avaliação da uniformidade de distribuição de água foram instalados 32 coletores na área experimental, sendo 16 em cada sistema de cultivo.

O monitoramento do conteúdo de água no solo (\% em volume) foi efetuado por meio de uma sonda de capacitância modelo Diviner $2000^{\circledR}$ da Sentek Pty Ltda, Austrália. Para tal, instalou-se seis tubos de PVC (três em cada sistema de cultivo), próprios para leitura do equipamento, com $0,7 \mathrm{~m}$ de comprimento. As leituras de frequência relativa (FR) foram realizadas de segunda à sexta-feira, pela manhã antes da irrigação e nas sextas no fim da tarde, após a irrigação. O equipamento media e registrava as FR em

Tabela 2. Características químicas do solo da área experimental.

\begin{tabular}{|c|c|c|c|c|c|c|c|c|c|c|c|}
\hline $\begin{array}{l}\text { Prof. } \\
(\mathrm{m})\end{array}$ & $\begin{array}{c}\text { M.O } \\
\text { g kg-1 }^{-1}\end{array}$ & $\begin{array}{c}\mathrm{pH} \\
\mathrm{H}_{2} \mathrm{O}\end{array}$ & $\begin{array}{c}P \\
\mathrm{mg} \mathrm{dm}^{-3}\end{array}$ & K & $\mathrm{Na}$ & Ca & $\begin{array}{r}\text { Mg } \\
\text { nmol }\end{array}$ & Al & $\mathrm{H}+\mathrm{Al}$ & CTC & $\begin{array}{l}\mathbf{V} \\
\%\end{array}$ \\
\hline $0,0-0,2$ & 7,7 & 6,1 & 34,4 & 0,2 & 0,04 & 2,2 & 0,5 & 0,05 & 1,4 & 4,5 & 66,8 \\
\hline $0,2-0,4$ & 8,5 & 6,0 & 25,1 & 0,2 & 0,04 & 2,1 & 0,5 & 0,05 & 1,9 & 4,9 & 60,0 \\
\hline
\end{tabular}


camadas de solo de 0,1 $\mathrm{m}$ até a profundidade de 0,6 m. Os valores de FR foram convertidos em percentagem de água no solo $(\theta)$ por meio de equação calibrada para o solo da área experimental (Silva et al., 2007). O período de monitoramento estendeu-se dos 19 dias após a semeadura até a colheita.

A estimativa da evapotranspiração diária da cultura (ETC), em cada sistema de plantio, foi efetuada por meio da diferença diária do armazenamento de água no solo, em camadas de 0,1 m, até a profundidade de 0,6 $\mathrm{m}$ (equações 1 e 2). Desconsiderou-se a drenagem profunda já que não houve variação significativa na umidade do solo além da camada de 0,6m, indicando que a dinâmica de água no solo limitou-se apenas até a essa camada.

$$
\begin{aligned}
& \operatorname{Arm}_{i}=\sum_{j=0,1}^{j=0,6} \theta_{j} Z_{j} \\
& \operatorname{ETc}_{i}=\operatorname{Arm}_{i}-\operatorname{Arm}_{i+1}
\end{aligned}
$$

\section{Em que:}

- armazenamento de água no solo no dia $i$ (mm);

- conteúdo de água no solo, em base volumétrica, na ca$\operatorname{madaj}\left(\mathrm{m}^{3} \mathrm{~m}^{-3}\right)$;

- espessura da camada de solo avaliadaj ( $\mathrm{mm})$;

- evapotranspiração da cultura no dia $i(\mathrm{~mm})$;

- armazenamento de água no solo no dia $i(\mathrm{~mm})$;

- armazenamento de água no solo no dia i+1 (mm).

O coeficiente de cultura $(\mathrm{Kc})$, em cada fase de desenvolvimento do feijão-caupi, foi calculado pela equação 3. Para tanto, o ciclo de cultivo foi dividido em quatro fases, a saber: I - da semeadura até 15 dias após a semeadura (DAS); II - de 16 até 34 DAS; III - de 35 até 53 DAS e IV - de 54 DAS à colheita.

$$
K c_{f}=\frac{\sum_{f=1}^{f=4} E T c_{f}}{\sum_{f=1}^{f=4} E T o_{f}}
$$

\section{Em que:}

- coeficiente de cultura do feijão-caupi na fase $f$ (adimensional);

- somatório da ETc do feijão-caupi na fase f (mm) (f variando de 1 a 4);

- somatório da ETo na fase f (mm) (f variando de 1 a 4)

Por ocasião da colheita (29/08/2016) quantificou-se a produtividade de grãos corrigida a $13 \%$ de umidade. Para tanto, selecionou-se quatro subáreas com cinco fileiras de plantas, com 4 m de comprimento, em cada sistema de cultivo.

Procedeu-se a estimativa da economia de água (EA), em cada fase de desenvolvimento do feijão-caupi e todo o ciclo de cultivo, proporcionada pela adoção do sistema plantio direto em relação ao sistema convencional (equação 4):

$$
E A_{f}=\left(\frac{E T c_{P C}-E T c_{P D}}{E T c_{P C}}\right) 100
$$

Em que:

- economia de água na fase $f(\%)$;

- ETc do feijão-caupi sob sistema de cultivo convencional $(\mathrm{mm})$

- ETc do feijão-caupi sob sistema de cultivo plantio direto (mm).

\section{Resultados e Discussão}

Os valores das lâminas de irrigação aplicadas durante o ciclo da cultura são apresentados na Figura 1. No período compreendido entre a semeadura até 11 DAS do feijão-caupi, as irrigações totalizaram 27,2 mm, que assegurou

Figura 1. Lâminas de irrigação aplicadas dos 11 aos 57 dias de cultivo do feijão-caupi, cultivar BRS Itaim. Teresina, PI, 2016.

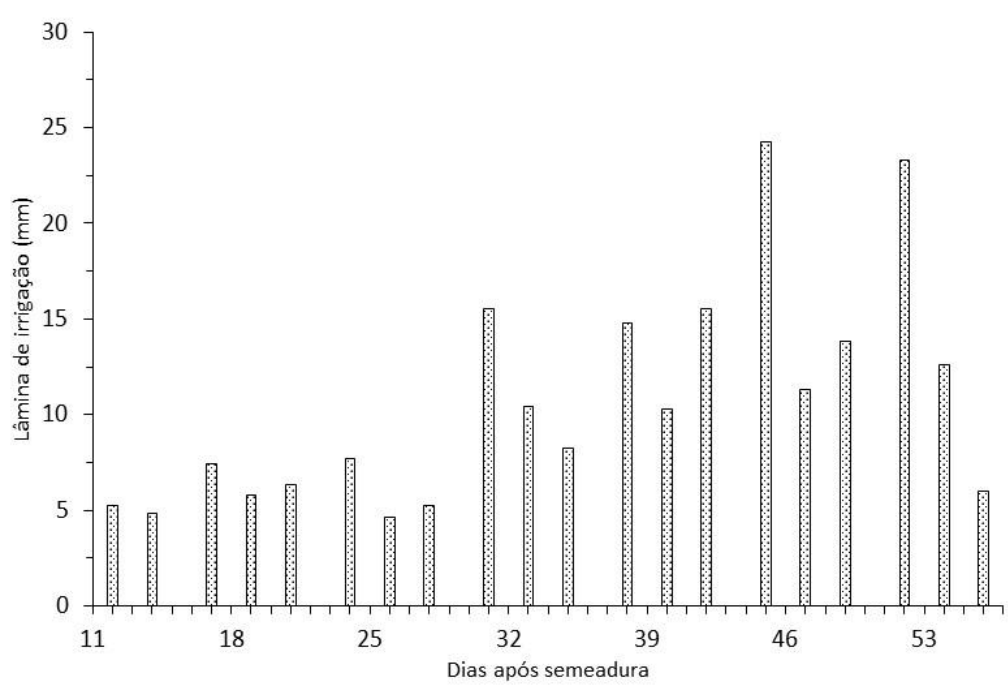


a emergência e o estabelecimento inicial das plantas. Dos 11 aos 57 DAS, aplicou-se uma lâmina total de irrigação de $246,8 \mathrm{~mm}$, o que totalizou durante todo o ciclo de cultivo uma lâmina total de irrigação de $274,0 \mathrm{~mm}$, distribuídas em 20 irrigações. Não houve registro de precipitação durante a condução do ensaio. Trabalhos na literatura relatam alcance de produtividades de grãos de feijão-caupi da ordem de 1.275 a $1.600 \mathrm{~kg} \mathrm{ha}^{-1}$, com a aplicação de lâminas de irrigação variando de 157,3 mm a 390,0 mm (Locatelli et al., 2014). O potencial produtivo do feijão-caupi é altamente dependente do material genético, sistema de cultivo e práticas de manejo adotadas (Cardoso et al., 2017).

A aplicação desse regime hídrico proporcionou variação no conteúdo de água no solo durante o ciclo de cultivo do feijão-caupi diferente para cada sistema de cultivo (Figura 2). Em ambos os sistemas de cultivo, a umidade do solo sempre se manteve acima da umidade crítica para o feijão-caupi (15\%), notadamente na camada de 0,2 a 0,6 m, indicando que a cultura não sofreu estresse hídrico. Por outro lado, em superfície (0,1 m), os níveis de umidade do solo aproximaram-se da umidade crítica, especialmente sob sistema de preparo convencional do solo (Figuras 2A a 2D). A cobertura do solo com palhada atua na primeira fase do processo de evaporação da água do solo, reduzindo a taxa de evaporação, em razão da reflexão e da absorção da energia incidente, que se relaciona à cor, ao tipo, à quantidade e à distribuição da palha das culturas anteriores (Stone e Moreira, 2000; Andrade et al., 2002; Stone et al., 2006). Assim, o solo se mantém mais úmido nas camadas superficiais quando sob presença de palhada em superfície.

Em todas as fases de desenvolvimento, sob sistema de preparo convencional do solo, os níveis de umidade do solo reduziram-se a partir de $0,3 \mathrm{~m}$ de profundidade no perfil do solo, enquanto que no sistema de cultivo sob plantio direto, os níveis de umidade do solo mantiveram-se elevados, bem superiores a umidade crítica, chegando até a superar a umidade à capacidade de campo na fase IV até a profundidade de 0,6 m. Essa tendência pode estar asso-
Figura 2. Umidade do solo durante o ciclo de cultivo do feijão-caupi, cultivar BRS Itaim, cultivado sob plantio direto (linha preta tracejada) e preparo convencional (linha cinza cheia). Teresina, PI, 2016. A - Todo ciclo, B - Fase II, C - Fase III, D - Fase IV, Capacidade de campo - linha cheia, Umidade Crítica - linha pontilhada e tracejado curto e Ponto de murcha permanente - linha tracejado longo.
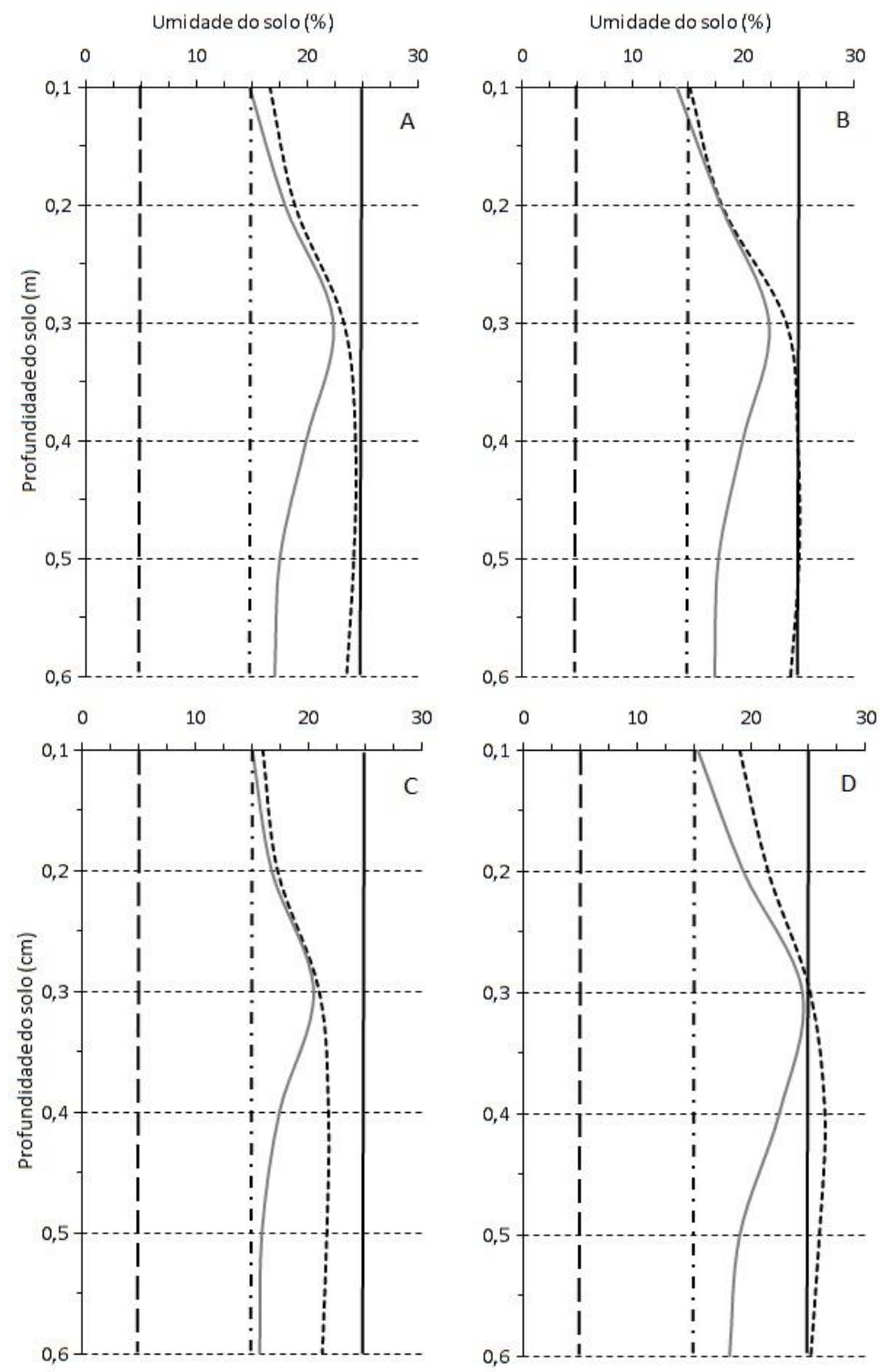
ciada ao aumento da taxa de infiltração de água (Urchei., 1996; Silveira et al., 2008; Stone e Silveira, 2001), bem como a redução da evaporação da água no solo promovida pela presença da palhada no sistema sob plantio direto.

A presença de palhada na superfície também promove a redução da velocidade do escoamento superficial, aumentando o tempo de oportunidade para a infiltração, devido ao aumento da rugosidade hidráulica do percurso ao longo do qual ocorre o escoamento. Assim, aliando-se o efeito da cobertura ao da maior estabilidade estrutural, a infiltração de água no solo sob plantio direto tem sido mais elevada que em outros sistemas de preparo, ocasionando menor perda de água por escorrimento superficial (Stone et al., 2012). A maior disponibilidade de água no solo em profundidade predispõe o feijão-caupi cultivado sob sistema plantio direto a tolerar períodos maiores de estiagem, quando cultivado sob sequeiro, ou maiores intervalos entre irrigações, em regime irrigado (Stone et al., 2012).

Os valores de evapotranspiração acumulada do feijão-caupi, cultivar BRS Itaim, sob sistema de cultivo convencional (PC) e plantio direto (PD), no período de 11 a 57 dias são apresentados na Figura 3. Os valores de ETc do feijãod caupi sob preparo convencional e plantio direto, de 11 a 57 DAS, totalizaram 130,2 $\mathrm{mm}$ e $110,8 \mathrm{~mm}$, respectivamente, resultando em uma economia de água da ordem de 14,9\%. A literatura relata que o feijão-caupi possui requerimento de água na faixa entre $250-300 \mathrm{~mm}$, que varia com época do ano, cultivar, sistema de cultivo e manejo de irrigação (Andrade Junior et al., 2002). Ressalta-se que no presente estudo a ETc foi computada apenas para um período de 46 dias (De 11 a 57 DAS), que aliada ao período de baixa demanda atmosférica (junho - agosto) podem ter contribuído para redução do requerimento de água pela cultura.
Nascimento et al. (2001) verificaram que a demanda total de água para o feijoeiro sob preparo convencional do solo foi de $325 \mathrm{~mm}$, enquanto que sob plantio direto a demanda foi de $260 \mathrm{~mm}$, representando uma redução de $20 \%$ do total de água aplicado no preparo convencional, bem próxima à economia de água obtida no presente estudo.

Em estudo conduzido por Bizari et al. (2009), a ETc do feijoeiro comum (Phaseolus vulgaris) em sistema plantio direto foi de $223,5 \mathrm{~mm}$, enquanto que no sistema convencional o consumo foi de $260,6 \mathrm{~mm}$, representando uma economia de água de 14,2\%. Tendência muito semelhante a obtida no presente estudo, apesar dos valores de requerimento de água terem sido superiores aos obtidos pelo feijão-caupi. o maior requerimento de água pelo feijão comum é explicado, dentre outros fatores, por seu maior ciclo de cultivo em relação ao feijão-caupi.

Stone e Moreira (2000) verificaram que sob plantio direto com cobertura de palhada o uso da água pelo feijoeiro foi mais eficiente em relação ao plantio direto sem cobertura de palhada. Com a cultivar Safira, de plantas eretas, a produtividade obtida nesse último sistema, com $400 \mathrm{~mm}$ de água, foi semelhante à obtida com $240 \mathrm{~mm}$ no plantio direto com cobertura morta, representando uma economia de água de $40 \%$. Com a cultivar Aporé, por ter plantas prostradas, a economia foi menos expressiva, de $14 \%$, bem próxima a obtida no presente estudo. Resultados semelhantes aos relatados por Bizari et al. (2009), que obtiveram economia de água de $14 \%$ ao comparar o consumo de água do feijoeiro cultivado sob plantio direto e preparo convencional, em um Latossolo Vermelho, em Campinas, SP.

A diferença no requerimento de água entre os sistemas de cultivo começa a se manifestar já no final da fase II, vindo a ampliar-se mais nas fases III, de maior requerimento
Figura 3. Evapotranspiração acumulada do feijão-caupi, cultivar BRS Itaim, sob sistema de cultivo convencional (PC) e plantio direto (PD). Teresina, PI, 2016.

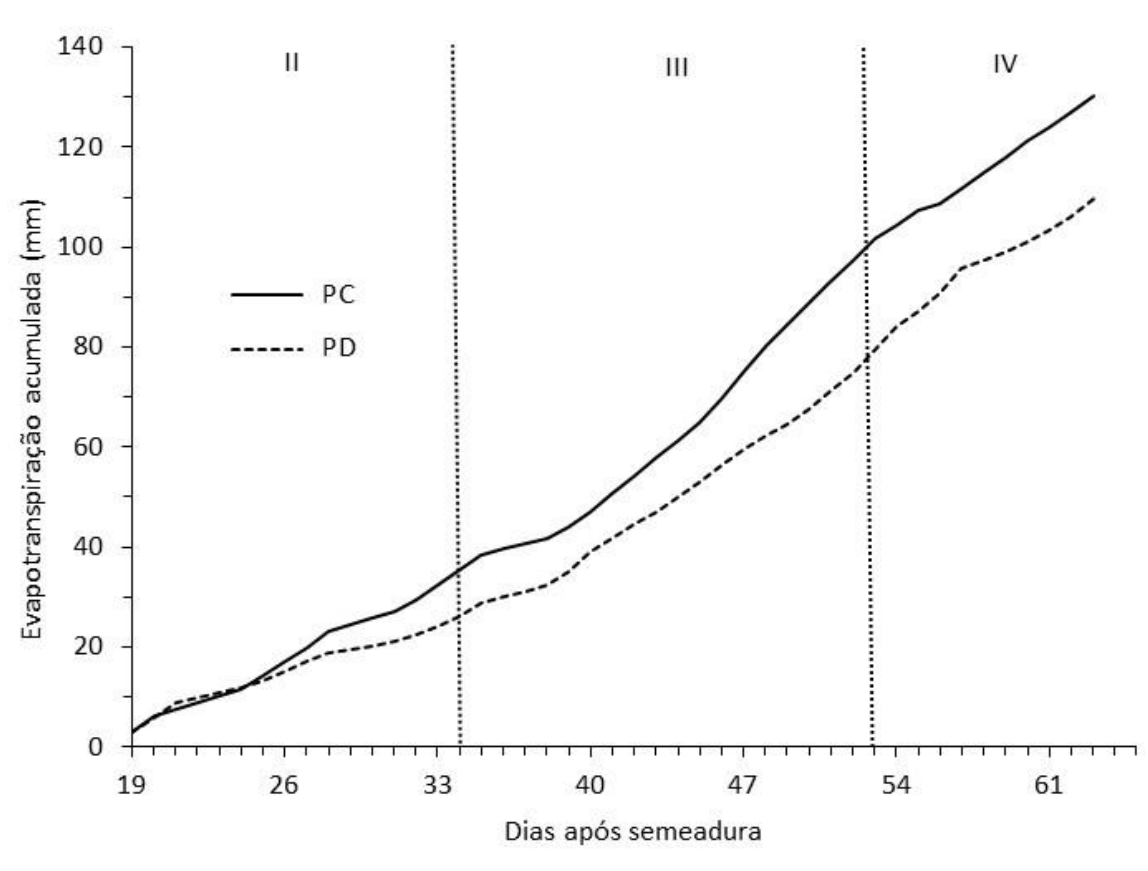

Agrometeoros, Passo Fundo, v.26, n.1, p.191-199, jul 2018. 195 
hídrico pelo feijão-caupi, e fase de maturação (Figura 3). Segundo Stone et al. (2006), avaliando o efeito na economia de água de diferentes culturas de cobertura do solo, concluíram que as maiores diferenças entre as palhadas das culturas de cobertura, com relação à ETc do feijoeiro, ocorreram nos estádios iniciais e finais do ciclo, em que as plantas do feijoeiro cobriam menos o solo, corroborando com a mesma tendência do presente estudo. Andrade et al. (2002) verificaram que a evapotranspiração da cultura do feijoeiro apresentou ao final do ciclo valores menores à medida que a porcentagem de cobertura do solo pela palhada foi maior.

As diferenças em termos de ETc entre os dois sistemas de cultivo deveram-se mais à dinâmica da água nas camas das mais superficiais do solo, como já relatado anteriormente. $\mathrm{Na}$ camada de $0-0,1 \mathrm{~m}$, sob sistema de preparo convencional, houve extração de $64,6 \%$ da água no solo para o processo evapotranspirativo, enquanto sob plantio direto a contribuição dessa camada foi de $57,4 \%$. As taxas de extração de água nas camadas de 0,1-0,2 $\mathrm{m}$ e de 0,2 - 0,3 $\mathrm{m}$ foram inferiores e bem semelhantes entre os dois sistemas de cultivo (Figura 4). Na camada de 0,1-0,2 m, as taxas de extração de água foram muito semelhantes nos dois sistemas de cultivo e iguais a $25,6 \%$, em PC, e de $27,8 \%$, sob PD. Porém, na camada de $0,2-0,3 \mathrm{~m}$, houve redução na taxa de extração de água sob preparo convencional para $9,8 \%$, enquanto sob sistema plantio direto a extração de água foi superior e igual a 14,8\%. As taxas de extração de água nas camadas de 0,4-0,6 m não contribuíram para a ETc do feijão-caupi em ambos os sistemas de cultivo. Isso deveu-se ao fato do sistema radicular efetivo do feijão-caupi situar-se até os $30 \mathrm{~cm}$ de profundidade do solo.

Os valores de evapotranspiração de referência (ETo), evapotranspiração da cultura (ETc) e coeficiente de cultura (Kc) por fases de desenvolvimento do feijão-caupi, cultivar BRS Itaim são apresentados na Tabela 3.

Durante as fases II e III de desenvolvimento do feijão-caupi, os valores de ETc no sistema de cultivo sob plantio direto foram inferiores aos obtidos sob preparo convencional. Contudo, não houve diferença sensível nos valores de ETc na fase IV entre os dois sistemas de cultivo. Redução nos valores de ETC nas fases iniciais de desenvolvimento do feijoeiro cultivado sob plantio direto também foram observados por Stone e Silva (1999) e Stone et al. (2006). Essa redução deveu-se notadamente ao decréscimo na taxa de evaporação de água no solo nos estágios iniciais de desenvolvimento do feijoeiro (Stone et al., 2006; Bizari et al., 2009).

Os valores de ETc nas fases II e III de desenvolvimento do feijão-caupi sob plantio direto foram menores que aqueles registrados no sistema de plantio convencional (Tabela 3). Em consequência dessa redução dos valores de ETc, os valores de Kc do feijão-caupi nessas mesmas fases foram menores, enquanto que para a fase IV não houve variação expressiva. Na fase II, os valores de Kc do feijão-caupi sob preparo convencional foi igual a 0,57 ao passo que sob plantio direto foi igual a 0,44 , uma redução de $22,8 \%$. Durante a fase III, de maior exigência hídrica do feijão-caupi, ocorreu redução um pouco maior entre os valores de $\mathrm{Kc}$ nos dois sistemas de cultivo ( $\mathrm{Kc}=1,32$, sob preparo convencional, e $\mathrm{Kc}=1,01$, em plantio direto). Em termos médios, durante todo o ciclo de cultivo, houve redução de $16,9 \%$ nos valores de Kc do feijão-caupi cultivado sob plantio direto em comparação ao preparo convencional.

Stone e Silva (1999) obtiveram valor de Kc igual a 1,06 no estádio da emergência até a floração/enchimento de grãos do feijoeiro sob plantio direto. Steinmetz (1984), para esse mesmo estádio, obteve Kc de 1,28 quando o feijoeiro foi cultivado em sistema convencional. Comparando-se os dois sistemas de cultivo, o sistema plantio direto propiciou uma economia de água em torno de 17\%, muito próxima da redução obtida no presente estudo, mesmo com espécies diferentes de feijão e sob condições edafoclimáticas distintas.

Bizari et al. (2009) encontraram valores de Kc para o feijoeiro, sob sistema de cultivo plantio direto, iguais a 0,79 (fase I), 0,88 (fase 2), 1,11 fase (III) e 1,13 (fase IV), os quais foram inferiores aos obtidos sob preparo convencional $(0,79 ; 1,18 ; 1,24$ e 1,15 , para as fases de I a IV, respectivamente), o que significou uma economia de água de $14 \%$, corroborando com a mesma tendência de redução observada no presente estudo.

A taxa de redução no requerimento de água depende da magnitude da cobertura com palhada e da arquitetura e desenvolvimento do dossel da planta cultivada. Assim, quando a palhada é pouca ou é rapidamente decomposta,

Tabela 3. Evapotranspiração de referência (ETo), evapotranspiração da cultura (ETc), coeficiente de cultura (Kc) e economia de água (EA), por fases de desenvolvimento do feijão-caupi, cultivar BRS Itaim, cultivado em preparo convencional (PC) e plantio direto (PD). Teresina, PI, 2016.

\begin{tabular}{|c|c|c|c|c|c|c|c|c|}
\hline \multirow{2}{*}{ Fases } & \multirow{2}{*}{$\mathrm{DAS}^{1}$} & \multirow{2}{*}{$\begin{array}{c}\text { ETo } \\
(\mathrm{mm})\end{array}$} & \multicolumn{2}{|c|}{ ETc (mm) } & \multirow{2}{*}{ EA (\%) } & \multicolumn{3}{|c|}{ Kc } \\
\hline & & & PC & PD & & PC & PD & $\Delta(\%)$ \\
\hline I & $0-15$ & --- & --- & --- & --- & --- & --- & --- \\
\hline II & $16-342$ & 47,7 & 27,0 & 21,0 & 22,2 & 0,57 & 0,44 & 22,8 \\
\hline III & $35-53$ & 46,8 & 61,9 & 47,2 & 23,7 & 1,32 & 1,01 & 23,5 \\
\hline IV & $54-67$ & 70,1 & 41,2 & 41,9 & $-1,6$ & 0,59 & 0,60 & $-1,6$ \\
\hline Ciclo & $16-67$ & 164,5 & 130,2 & 110,8 & 14,9 & 0,83 & 0,69 & 16,9 \\
\hline
\end{tabular}

1 - Dias após semeadura; 2 - início do monitoramento da água no solo aos 19 DAS. 
Figura 4. Extração acumulada de água do solo promovida por evaporação e pelas raízes do feijão-caupi, cultivar BRS Itaim, sob sistema de cultivo convencional (A) e plantio direto (B). Teresina, PI, 2016.

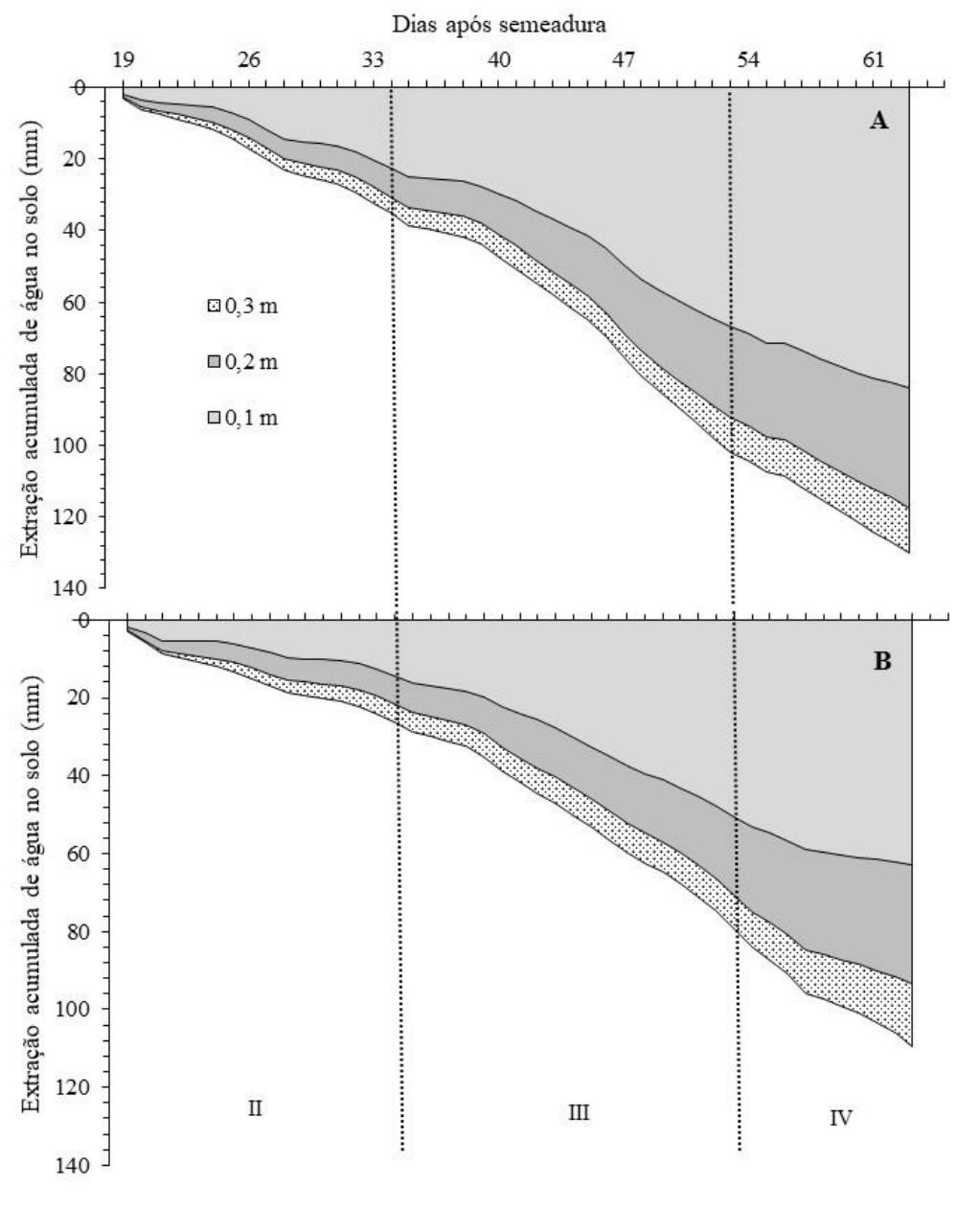

e a cultura cobre rapidamente o solo, esse benefício não é tão expressivo. No caso do presente estudo, os ensaios foram executados em área com cultivo sob palhada de apenas três anos. Acredita-se que a economia de água possa tornar-se mais relevante com ciclos sucessivos de culturas de cobertura do solo, proporcionando melhor formação de palhada na superfície do solo.

A produtividade de grãos ( $\mathrm{PG}$ ) obtida no sistema de cultivo sob preparo convencional foi de $984,4 \mathrm{~kg} \mathrm{ha}^{-1}$, enquanto sob plantio direto foi de $1.238,1 \mathrm{~kg} \mathrm{ha}^{-1}$, cerca de 25,8\% superior. Em ensaios conduzidos sob irrigação na região de Teresina, PI, Freire Filho et al. (2009) obtiveram, com a cultivar BRS Itaim, produtividade de grãos de $956 \mathrm{e}$ $1.193 \mathrm{~kg} \mathrm{ha}^{-1}$, muito próximos do alcançado neste estudo. A superioridade na produção de grãos deveu-se à maior disponibilidade de água no solo para as plantas na condição do cultivo sob palhada, corroborando os resultados obtidos por Stone e Moreira (2000) com a cultura do feijoeiro.

\section{Conclusões}

A evapotranspiração do feijão-caupi sob plantio direto é inferior ao cultivado sob preparo convencional. Houve redução média de $16,9 \%$ nos coeficientes de cultivo (Kc) do feijão-caupi cultivado sob plantio direto em relação ao sistema de preparo convencional. o cultivo do feijão-caupi sob plantio direto economiza $14,9 \%$ de água em comparação ao preparo convencional do solo.

\section{Referências Bibliográficas}

ALLEN, R. G.; PEREIRA, L. S.; RAES, D.; SMITH, M. Crop evapotranspiration: guidelines for computing crop water requirements. Roma: $\mathrm{FAO}$, 1998. 328p. (FAO Irrigation and Drainage Papers, 56).

ANDRADE JÚNIOR, A. S.; RODRIGUES, B. H.; FRIZZONE, J. A.; CARDOSO, M. J.; BASTOS, E. A.; MELO, F. B. Níveis de irrigação na cultura do feijão caupi. Revista Brasileira de Engenharia Agrícola e Ambiental, v. 6, n. 1, p. 17-20, 2002

ANDRADE, R.S.; MOREIRA, J. A. A.; STONE, L. F.; CARVALHO, J. de A. Consumo relativo de água do feijoeiro no plantio direto em função da porcentagem de cobertura morta do solo. Revista Brasileira de Engenharia Agrícola e Ambiental, Campina Grande, v. 6, n. 1, p. 35-38, 2002.

BARROS, L.C.G.; HANKS, R.J. Evapotranspiration and yield of beans as affected by mulch and irrigation. Agronomy Journal, Madison, v.85, p.692-697, 1993.

BASTOS, E. A.; ANDRADE JUNIOR, A. S. Boletim Agrometeorológico de 2015 para o município de Teresina, Piauí. Teresina: Embrapa MeioNorte, 2016.38p. (Documentos / Embrapa Meio-Norte, ISSN 0104 - 866X; 239).

BIZARI, D.R.; MATSURA, E.E.; ROQUE, M.W.; SOUZA, A.L. Consumo de água e produção de grãos do feijoeiro irrigado em sistemas plantio direto e convencional. Ciência Rural, Santa Maria, v.39, n.7, p. 2073-2079, 2009. 
CARDOSO, M.J.; BASTOS, E.A.; ATHAYDE SOBRINHO, C.; MELO, F.B. Rendimento de grãos do feijão-caupi BRS Itaim em função da densidade de plantio em sistemas de semeadura convencional e direta com palhada do primeiro ano. Teresina: Embrapa Meio-Norte, 2017. 7p. (Comunicado Técnico / Embrapa Meio-Norte, ISSN 0104-7647; 240).

FREIRE FILHO, F. R. (Ed.). Feijão-caupi no Brasil: produção, melhoramento genético, avanços e desafios. Teresina: Embrapa Meio-Norte, 2011. 84 p.

FREIRE FILHO, F. R.; ROCHA, M.M.; RIBEIRO, V.Q.; SILVA, K.J.D.; CARVALHO, H.W.L.; CRAVO, M.S.; LOPES, A.M.; VILARINHO, A.A.; SABOYA, R.C.C.; CAVALCANTE, E.S.; COSTA, A.F.; ALCANTARA, J.P.; SITTOLIN, I.M. BRS Itaim: cultivar de feijão-caupi com grãos tipo fradinho. Teresina: Embrapa Meio-Norte, 2009. 2p.

LOCATELLI, V. da E.R.; MEDEIROS, R.D. de; SMIDERLE, O. J.; ALBUQUERQUE, J. de A. A.; ARAÚJO, W. F.; SOUZA, K. T. S. de. Componentes de Produção, produtividade e eficiência da irrigação do feijão-caupi no cerrado de Roraima. Revista Brasileira de Engenharia Agrícola e Ambiental, v. 18, n. 6, p. 574-580, 2014.

MELO, F. B.; CARDOSO, J. C. Solos e adubação. In: BASTOS, E. A. Cultivo de feijão-caupi. 2. ed. Brasília, DF: Embrapa Meio-Norte, 2017.

MELO, F. de B.; ANDRADE JUNIOR, A. S. de; PESSOA, B. L. de O. Levantamento, zoneamento e mapeamento pedológico detalhado da área experimental da Embrapa Meio-Norte em Teresina, PI. Teresina: Embrapa Meio-Norte, 2014. 47 p. (Embrapa Meio-Norte. Documentos, 231).

NASCIMENTO, J. L. do; STONE, L. F.; OLIVEIRA, L. F. C. de. Demanda total de água do feijoeiro nos sistemas de plantio convencional e direto. Pesquisa Agropecuária Tropical, Goiânia, v. 31, n. 2, p. 159-161, 2001.

SILVA, C.R.; ANDRADE JÚNIOR, A.S.; ALVES JÚNIOR, J.; SOUSA, A.B.; MELO, F.B.; COELHO FILHO, M.A. Calibration of Diviner $2000^{\circledR}$ capacitance probe in a Rhodic Paleudult. Scientia Agricola, Piracicaba, v. 64, p. 636640,2007

SILVEIRA, P.M.; STONE, L.F.; ALVES JÚNIOR, J.; SILVA, J.G. Efeitos do manejo do solo sob plantio direto e de culturas na densidade e porosidade de um Latossolo. Bioscience Journal, Uberlândia, v. 24, n. 3, p. 53-60, 2008.
SIMIDU, H.M.; SÁ, M.E.; SOUZA, L.C.D.; ABRANTERS, F.L.; SILVA, M.P.; ARF, O. Efeito do adubo verde e época de semeadura sobre a produtividade do feijão, em plantio direto em região de cerrado. Acta Scientiarum Agronomy, v. 32, n. 2, p. 309-315, 2010.

STEINMETZ, S. Evapotranspiração máxima no cultivo do feijão de inverno. Goiânia: EMBRAPACNPAF, 1984. 4 p. (EMBRAPA-CNPAF. Pesquisa em andamento, 47).

STONE, L.F.; MOREIRA, J.A.A. Efeitos de sistemas de preparo do solo no uso da água e na produtividade do feijoeiro. Pesquisa Agropecuária Brasileira, Brasília, DF, v. 35, n. 4, p. 835-841, 2000.

STONE, L.F.; SILVA, S.C. Uso do tanque Classe A no controle da irrigação do feijoeiro no sistema plantio direto. Santo Antônio de Goiás: Embrapa Arroz e Feijão, 1999. 2 p. (Embrapa Arroz e Feijão. Pesquisa em foco, 25).

STONE, L.F.; SILVEIRA, P.M. Efeitos do sistema de preparo do solo e da rotação de culturas na porosidade e densidade do solo. Revista Brasileira de Ciência do Solo, Viçosa, MG, v. 25, n. 2, p. 395401, 2001.

STONE, L.F.; SILVEIRA, P.M.; MOREIRA, J.A.A.; BRAZ, A.J.B.P. Evapotranspiração do feijoeiro irrigado em plantio direto sobre diferentes palhadas de culturas de cobertura. Pesquisa Agropecuária Brasileira, Brasília, DF, v. 41, n. 4, p. 577-582, 2006.

STONE, L.F.; SILVEIRA, P.M.; MOREIRA, J.A.A. Efeitos do sistema plantio direto no uso da água pelas culturas e no manejo da irrigação. Santo Antônio de Goiás: Embrapa Arroz e Feijão, 2012. 8p. (Embrapa Arroz e Feijão. Comunicado Técnico, 207).

URCHEI, M. A. Efeitos do plantio direto e do preparo convencional sobre alguns atributos físicos de um Latossolo vermelho-escuro argiloso e no crescimento e produtividade do feijoeiro (Phaseolus vulgaris L.) sob irrigação. 1996. 131 f. Tese (Doutorado em Irrigação e Drenagem) - Universidade Estadual Paulista, Botucatu.

REFERENCIAÇÃO ANDRADE JUNIOR, A. S.; BASTOS, E. A.; MONTEIRO, M. M. S.; JOSIMAR SOARES DA SILVA JUNIOR, J. S. Evapotranspiração e coeficiente de cultura do feijão-caupi sob sistema de cultivo convencional e plantio direto. Agrometeoros, Passo Fundo, v.26, n.1, p.191-199, 2018. 


\title{
Evapotranspiration and cowpea crop coefficient under conventional tillage and no-tillage cropping system
}

\author{
Aderson Soares de Andrade Junior ${ }^{1\left(^{*}\right)}$, Edson Alves Bastos ${ }^{1}$, Marinete Martins de Sousa Monteiro ${ }^{2}$ and \\ Josimar Soares da Silva Junior ${ }^{2}$ \\ ${ }^{1}$ Embrapa Meio-Norte, Avenida Duque de Caxias, 5.650, Bairro Buenos Aires, Caixa Postal 001, CEP 64008-780 Teresina, PI, Brazil. \\ E-mails: aderson.andrade@embrapa.br and edson.bastos@embrapa.br \\ ${ }^{2}$ UFPI-Programa de Pós-graduação em Agricultura Tropical, Campus Universitário Ministro Petrônio Portela, Bairro Ininga, CEP 64049-550 Teresina, PI, \\ Brazil. E-mails: marinettmartins@hotmail.com and josimarssjunior@gmail.com \\ ${ }^{(*)}$ Corresponding author.
}

\section{ARTICLE INFO}

Article history:

Received 23 June 2018

Accepted 2 December 2018

\section{Index terms:}

water balance

climatic risk

$\mathrm{Kc}$

water demand

\section{ABSTRACT}

The objective of this study was to quantify and compare the evapotranspiration (ETc) and crop coefficients (Kc), as well as to evaluate the water economy provided by the adoption of the no-tillage system in relation to the conventional crop in the cowpea in Teresina, PI. The study was conducted in the Experimental Field of Embrapa Middle-North, in Teresina, Piauí, Brazil (5 ${ }^{\circ} 05^{\prime} \mathrm{S}, 42^{\circ} 29^{\prime} \mathrm{W}$ and $74.40 \mathrm{~m}$ altitude), from June to August 2016, in a Red-Yellow Argisol, sandy texture. The daily ETc was measured by means of the daily soil water storage difference in layers of $0.1 \mathrm{~m}$ until the depth of $0.6 \mathrm{~m}$. The ETc of cowpea under no-tillage is $14.9 \%$ lower than that under conventional tillage. There was an average reduction of $16.9 \%$ in the Kc of cowpea cropping under no-tillage compared to the conventional tillage system. 